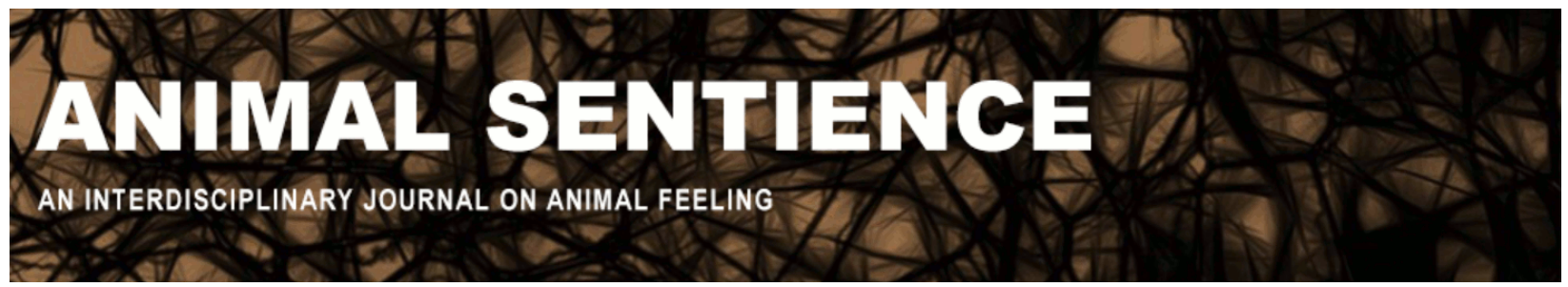

Fawcett, Anne (2016) Veterinarians need support to break the silence. Animal Sentience 6(2)

DOI: $10.51291 / 2377-7478.1082$

Date of submission: 2016-01-22

Date of acceptance: 2016-01-22

(c)

This article has appeared in the journal Animal

Sentience, a peer-reviewed journal on animal

cognition and feeling. It has been made open access,

free for all, by WellBeing International and deposited

in the WBI Studies Repository. For more information,

please contact

wbisr-info@wellbeingintl.org.

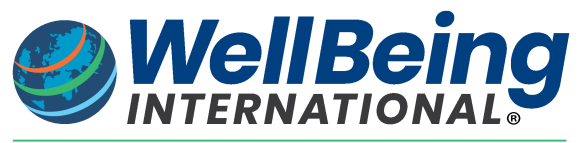

SOLUTIONS FOR PEOPLE, ANIMALS AND ENVIRONMENT 


\title{
Veterinarians need support to break the silence
}

Commentary on Lachance on Breaking Silence

\author{
Anne Fawcett \\ Faculty of Veterinary Science \\ University of Sydney
}

\begin{abstract}
The question of whether reporting animal abuse should be mandatory for veterinarians is an important one. Veterinarians have dual obligations, both to their animal patients and to their human clients. Mandatory reporting can only be supported in a context in which veterinary professionals are (a) trained to recognise the signs of animal abuse; (b) trained to elicit a history sensitively from clients - who may themselves be victims of abuse or supported in doing so; (c) supported by appropriate, responsive authorities; (d) and reasonably protected from legal recriminations.
\end{abstract}

\begin{abstract}
Anne Fawcett anne.fawcett@sydney.edu.au is a lecturer in veterinary science studying animal welfare through the Australia and New Zealand College of Veterinary Scientists, and co-authoring a book on veterinary ethics with Dr. Siobhan Mullan from Bristol University (to be published by Nottingham University Press in 2016).

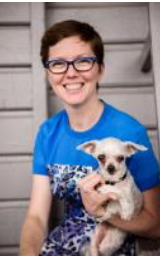
http://sydney.edu.au/vetscience/about/staff/profiles/anne.fawcet t.php
\end{abstract}

Lachance (2016) makes an impassioned plea for the uniform introduction of mandatory reporting of animal abuse by veterinarians. Veterinarians have dual obligations, both to their animal patients and their human clients. One of the sources of moral stress in veterinary practice is when these obligations conflict. In the context of animal abuse, for example, our obligation to uphold the confidentiality of discussions with a client who confides that her partner deliberately injured the animal may conflict with our obligations to look after the animal (for example, reporting the abuse to authorities).

Lachance observes that "many veterinarians hesitate to report animal mistreatment because they fear economic, physical and legal reprisal."

In particular, there is a valid concern that reporting abuse to authorities breaches client confidentiality. She argues, eloquently, that the protection of professional secrecy was not introduced in the spirit of cloaking criminal offences. This, together with the vulnerability of animals, and the well-documented link between acts of violence towards animals and acts of violence towards humans, creates a moral imperative for the veterinary professional to report suspected animal abuse. 
"Presented in this context," she argues, "mandatory reporting may appear to resolve the ethical dilemma of the practitioner.

As a practicing veterinarian, one who teaches veterinary ethics, I agree with Lachance. But I must question two assumptions made early in the discussion.

The first is that "Animals subject to abuse, if their aggressor does not kill them outright, usually end up in a veterinary clinic to be treated for their injuries." The truth is that we really don't know. Veterinary care may not be sought for myriad possible reasons: the injuries may not be perceived to be serious enough to warrant care, there may be fear that the veterinarian will identify the injury as non-accidental and may indeed by obligated to report suspected animal abuse (Acutt, Signal, et al. 2015), or veterinary care may not be financially or geographically accessible. Neglect, including failure to provide veterinary care, is also a form of abuse (Tong 2014). It may be that some animals present much later, when the evidence of abuse is less obvious. In one study, evidence of healing fractures suggested that presentation to a veterinarian was significantly delayed for some animals (Tong 2014). There is no way of knowing reliably what proportion of animal victims of abuse will be seen by veterinarians.

The second assumption is that veterinarians "are usually in a position to detect animal abuse." But animal abuse isn't always easily diagnosed. Differentiating deliberately induced or non-accidental injury (NAI) from accidental injury may be straightforward in some cases (for example, gunshot wounds, cigarette burns, asphyxia or microwave burns) but is quite challenging in others where the type of injury may be attributable to accidental or nonaccidental causes - particularly high-impact trauma (for example, bruising, lacerations, fractures, head injuries, or rupture of internal organs) (Tong 2014). In a study to determine the characteristics of fractures associated with NAI in dogs, these authors found significant differences between the injuries of animal victims of abuse compared with human victims of abuse. While there are some studies specifically looking at characteristics of NAI in animals 2014), veterinarians cannot base their assessments on data from the human NAI literature. Given the sensitivities surrounding NAl and the importance of identifying it, veterinarians may not be prepared to report suspected abuse without sufficient evidence, which may be difficult to gather. For example, in the case of investigating a non-accidental fracture, a combination of history, physical examination, radiographs, advanced imaging and specialist involvement may be required. As tests are performed on a user-pays basis, the client may decline investigations. Many veterinarians operate according to the principal of nonmaleficence (Beauchamp and Childress 2013) and may be acutely aware of potential harm to the relationship with the client if a false report is made.

One concern about mandatory reporting, which is written into the Australian Veterinary Association's policy, is that people may be reluctant to present animals to the veterinarian, thus potentially denying necessary treatment or rendering them vulnerable to further abuse. Interestingly, a community survey found that 76 percent of respondents incorrectly believed that the reporting of animal abuse by veterinary professionals is mandated, suggesting that 
concerns about animals not being presented to veterinarians for fear of reporting may be overstated (Acutt, Signal, and Taylor 2015).

Given that a high number of veterinarians report feeling ill-equipped to address concerns of abuse, there may be a role for veterinary social work - the provision of services at the intersection of veterinary medicine and social work - in clinical settings (Holcombe, Strand, Nugent, and Ng 2016). It is likely that only major veterinary teaching hospitals would be able to provide such a service.

Mandatory reporting can only be supported in a context in which veterinary professionals are (a) trained to recognise the signs of animal abuse; (b) trained to sensitively elicit a history from clients - who may themselves be victims of abuse - or supported in doing so; (c) supported by appropriate, responsive authorities; (d) and reasonably protected from legal recriminations.

Lachance is one researcher breaking the silence for animal victims of abuse who cannot speak for themselves. In addition to legislating mandatory reporting, we need to ensure that veterinarians are trained and supported so that they can diagnose animal abuse and deal with animal and human victims of abuse in a way that minimises harm, so that they are empowered to break the silence.

\section{References}

Acutt, D., T. Signal and N. Taylor (2015). Mandated reporting of suspected animal harm by australian veterinarians: Community attitudes. Anthrozoos 28(3): 437-447.

Beauchamp, T. L. and J. F. Childress (2013). Principles of biomedical ethics. New York, Oxford, Oxford University Press.

Holcombe, T. M., E. B. Strand, W. R. Nugent and Z. Y. Ng (2016). Veterinary social work: Practice within veterinary settings. Journal of Human Behavior in the Social Environment 26(1): 69-80.

Lachance, M. (2016). Breaking the silence: The veterinarian's duty to report. Animal Sentience 2016.006: 1-16.

Tong, L. J. (2014). Fracture characteristics to distinguish between accidental injury and nonaccidental injury in dogs. Veterinary Journal 199(3): 392-398. 